\title{
Research of the Influence of Zinc Ions on Synthesis and Properties of Hydroxyapatite ${ }^{\dagger}$
}

\author{
Dmitriy Fedorishin ${ }^{1}$, Anastasiya Gutsalova ${ }^{2}$, Daria Lytkina ${ }^{1}$ and Irina Kurzina ${ }^{1, *}$ \\ 1 Chemical Faculty, National Research Tomsk State University, Lenin 36, 634050 Tomsk, Russia; \\ strix187@yandex.ru (D.F.); darya-lytkina@yandex.ru (D.L.) \\ 2 National Research University ITMO, St. Petersburg, 197101, Russia; nastya_w@bk.ru (A.G.) \\ * Correspondence: kurzina99@mail.ru; Tel.: +7-913-882-1028 \\ + Presented at the 1st International Electronic Conference on Applied Sciences, 10-30 November 2020; \\ Available online: https://asec2020.sciforum.net/.
}

Published: 10 November 2020

\begin{abstract}
Hydroxyapatites modified with metal ions are the main inorganic components of bone tissue that are approved for use as components for biocomposites and coatings for surgical implants. This study examined prototypes of functional materials for bone implants based on hydroxyapatite modified with zinc ions. Antibacterial activity and biocompatibility have been established. The studied materials have antimicrobial activity, the samples did not cause significant changes both in the internal organs and in the general condition of laboratory animals during the entire experiment.
\end{abstract}

Keywords: zinc-modified hydroxyapatite; phase composition; biological activity; lactide-glycolide copolymer; composite material; surface morphology; cytotoxicity

\section{Introduction}

Currently, the fields of chemical materials science are actively developing, aimed at creating new multifunctional materials designed to improve the quality and longevity of the population. Such materials are widely used, mainly in various branches of medicine and pharmacology. The work belongs to an urgent scientific field - the development of new chemical agents for the treatment of socially significant diseases. Scientific novelty, originality and prospects of the research are associated with the synthesis and study of the physicochemical and biological characteristics of materials based on zinc-modified hydroxyapatites. Hydroxyapatite $\mathrm{Ca}_{10}\left(\mathrm{PO}_{4}\right)_{6}(\mathrm{OH})_{2}$ is a mineral from the apatite group. White crystalline powder, has low water solubility.

Hydroxyapatites modified with metal ions are the main inorganic components of bone tissue, approved for use as components for biocomposites and coatings for surgical implants. However, it should be noted that the effect of a biocompatible material on living tissues is very complicated due to the fact that an important factor is the metabolism of each bioresorbable component and its degradation products. At the tissue-material interface, the body's reactions to a foreign body occur. In this case, for example, acute inflammation is necessary for wound healing and restoration of homeostasis at the site of injury. However, the excessive pro-inflammatory properties of the material can cause a variety of pathologies leading to implant rejection. Therefore, it is difficult to compare and draw unambiguous conclusions about the biocompatibility of a particular material for implantation, based only on the results of in vitro or in vivo analysis. These processes should be considered exclusively in combination [1].

The composition of the bone can be approximately expressed by the formula $(\mathrm{Ca}, \mathrm{Na})_{10-x y}$ $\left(\mathrm{HPO}_{4}\right)_{x}\left(\mathrm{CO}_{3}\right)_{y}\left(\mathrm{PO}_{4}\right)_{6-x y}(\mathrm{OH})_{2-x y z}(\mathrm{Cl}, \mathrm{F})_{z}$, where in a young organism $\mathrm{x}+\mathrm{y} \sim 1.7$, with age, $\mathrm{x}$ decreases along with an increase in y [2]. In the crystal structure of apatite, partial replacement (substitution) of Proceedings 2020, 4, $\mathrm{x}$; doi: FOR PEER REVIEW www.mdpi.com/journal/proceedings 
calcium cations with other ions is possible, for example, $\mathrm{Zn}^{2+}, \mathrm{Ba}^{2+}, \mathrm{Be}^{2+}, \mathrm{Pb}^{2+}$. Cationic and anionic substitutions have a huge impact on the biological behavior of hydroxyapatite [1]. The crystal structure of HA allows various kinds of substitution of some elements by others, and certain atoms can occupy completely or only partially different positions in the structure of HA, as a result of which a variety of compositions of natural phosphates with apatite structure appears [3].

Zinc ions, based on the values of their radius, are able to replace calcium ions in the crystal lattice, which leads to a change in physicochemical and biological properties.

$\mathrm{Zn}^{2+}$ ions have bactericidal, bacteriostatic, antiviral and antiseptic action against more than 500 pathogenic microorganisms and viruses. Their antimicrobial effect is stronger than that of penicillin, biomycin, and other antibiotics due to the inhibitory effect on bacterial strains that are resistant to antibiotics [1] (Table 1).

Table 1. Ionic radii and electrochemical potentials of cations.

\begin{tabular}{lcc}
\hline Ion & Ionic Radius $\boldsymbol{r}_{\boldsymbol{i}}, \AA \mathrm{\AA}$ & Potential $\boldsymbol{\varphi} \cdot \mathbf{1 0 ^ { 2 2 }}, \mathrm{C}^{2} \mathbf{m}$ \\
\hline $\mathrm{Ca}^{2+}$ & 1.06 & 2,426 \\
\hline $\mathrm{Zn}^{2+}$ & 0.83 & 3,096 \\
\hline
\end{tabular}

The aim of this work is to study the effect of zinc ions on the biocompatibility of zinc-modified hydroxyapatite. The choice of this ion for the modification of hydroxyapatites was due to the fact that zinc is an important trace element necessary for the normal course of many biochemical processes [4]. Also, zinc ions in certain concentrations have antibacterial activity $[5,6]$.

\section{Materials and Research Methods}

A solution of calcium nitrate $(\mathrm{Cm}=0.5 \mathrm{~mol} / \mathrm{L})$ and ammonium hydrogen phosphate $(\mathrm{Cm}=0.31$ $\mathrm{mol} / \mathrm{L}$ ) was used as the initial components of the microwave synthesis of zinc-modified hydroxyapatite $(\mathrm{Zn} \times \mathrm{HA})$, observing the molar ratio of elements $\mathrm{Ca} / \mathrm{P}=5 / 3$ characteristic of hydroxyapatite. By varying the content of zinc nitrate during the synthesis, we obtained a line of samples with different amounts of mol of zinc $\mathrm{Ca}(10-\mathrm{x}) \mathrm{Z} \mathrm{n}_{\times}\left(\mathrm{PO}_{4}\right)_{6}(\mathrm{OH})_{2}$, where $\mathrm{x}=0.1 ; 0.5 ; 0.9$. The ratio of the components was determined using elemental analysis on a Quantax-70 attachment for energy dispersive microanalysis. Elemental analysis was performed before and after the in vivo experiment. To determine the antibacterial activity, the determination of the number of cells by sowing on solid nutrient media (Koch's method) was used according to the standard method of the author's modification [7]. To determine biocompatibility in vivo, the technique provided by GOST ISO 10993-1-2011 in the author's modification was used [7].

\section{Results}

The elemental composition of the synthesized ZnGA powders according to the results of X-ray diffraction analysis shows that the molar ratio of elements $(\mathrm{Ca}+\mathrm{Zn}) / \mathrm{P}$ is $1.4-1.9$, which corresponds to the ratio of $\mathrm{Ca} / \mathrm{P}$ elements for bone tissue (1.4-2.0) [2]. Elemental analysis, carried out after removing the samples from the body of experimental animals, showed that the concentration of zinc ions on the surface of the implants decreases by about $20-40 \%$ (Table 2). In this case, the higher the initial concentration of zinc in the samples, the higher its yield from them. 
Table 2. Results of elemental analysis of samples of the $\mathrm{Zn \Gamma A}$ group.

\begin{tabular}{cccccc}
\hline $\begin{array}{c}\text { Sample } \\
\mathbf{x}\left(\mathbf{Z n}^{2+}, \mathbf{m o l}\right) \text { is } \\
\text { introduced }\end{array}$ & $\mathbf{O}$ & $\mathbf{C a}$ & $\mathbf{P}$ & $\mathbf{Z n}$ & $\frac{\mathrm{Ca}+\mathrm{Zn}}{\mathrm{P}}$ \\
\cline { 2 - 6 } & \multicolumn{5}{c}{ Before in vivo } \\
\hline 0.1 & 67.47 & 18.76 & 13.69 & 0.18 & 1.38 \\
0.5 & 67.84 & 18.57 & 12.99 & 0.72 & 1.64 \\
0.9 & 70.94 & 18.08 & 9.93 & 1.06 & 1.93 \\
\hline \multicolumn{5}{c}{ After in vivo } \\
\hline 0.1 & 22.59 & 12.15 & 0.12 & 1.86 \\
0.5 & 64.90 & 12.17 & 0.36 & 1.90 \\
0.9 & 64.58 & 22.87 & 12.41 & 0.83 & 1.81 \\
\hline
\end{tabular}

The investigated samples showed antibacterial activity of varying intensity. At the same time, the Zno.1HA sample (Table 3) did not have an overwhelming effect on the number of E. coli. The number of bacteria in a liquid medium with this sample is slightly less than in the control sample, but the statistical significance of the differences has not been established $(p>0.05)$.

Samples $\mathrm{Zn} 0.5 \mathrm{HA}$ and $\mathrm{Zn} 0.9 \mathrm{HA}$ showed antibacterial activity, decreasing the number of bacteria in comparison with the control sample. The Zno.9HA sample showed the highest antibacterial activity among all the studied samples, reducing the number of bacteria by almost an order of magnitude $(p<0.001)$. Unmodified hydroxyapatite (HA) also had antimicrobial activity $(p<0.05)$. Its antimicrobial activity and cytotoxicity in in vivo studies is approximately equal to the Zno.1HA sample. Consequently, the Zno.1HA sample is approximately equal to HA in its biological effect (Table 4).

Table 3. Results of studying the antimicrobial activity of samples of the ZnHA group.

\begin{tabular}{ccc}
\hline № & Sample & CFU/mL \\
\hline 1 & Control & $(3.96 \pm 0.62) \times 10^{7}$ \\
\hline 2 & Zno.1HA & $(3.40 \pm 0.30) \times 10^{7}$ \\
\hline 3 & Zno.. HA & $(2.15 \pm 0.28) \times 10^{7}$ \\
\hline 4 & Zno.. HA & $(8.31 \pm 0.91) \times 10^{6}$ \\
\hline
\end{tabular}

Table 4. Results of studying the antimicrobial activity of HA.

\begin{tabular}{ccc}
\hline № & Sample & CFU/ml \\
\hline 1 & Control & $(1.98 \pm 0.91) \times 10^{10}$ \\
\hline 2 & HA & $(1.01 \pm 0.49) \times 10^{10}$ \\
\hline
\end{tabular}

As a result of an in vivo experiment, it was found that all studied materials caused a local rejection reaction of varying intensity. The reaction of local tissues to all samples of the $\mathrm{Zn \Gamma A}$ group was inflammatory, but not necrotic. This is confirmed by the presence of an intensive vascularization process and the formation of pronounced fibrous capsules. The local response to the HA group implants was similar to that of the Zn0.1GA group, therefore, the levels of their cytotoxicity are similar. The average weight of implants before the start of the experiment was 170-200 $\mathrm{mg}$, and after the end of the experiment-175-210 $\mathrm{mg}(p>0.05)$. Changes in the mass of implants are associated with the ingrowth of fibrous tissue into their surface. Resorption of implants while in the body of experimental animals was not found. A small change in mass may be due to a small release of ions from the implants. Low hemodiffusion at the insertion site can also be the reason for the lack of resorption of implants. A relationship was found between the concentration of zinc in the sample and its toxic effects. Samples with high levels of zinc ions caused more severe toxic effects than samples with low levels of zinc. 


\section{Conclusions}

Hydroxyapatites modified with zinc ions exhibit significant antimicrobial activity. Despite some cytotoxicity, these samples did not cause significant changes both in the internal organs and in the general condition of laboratory animals during the entire experiment.

Author Contributions: Conceptualization I.K.; methodology, investigation A.G.; D.L.; D.F.; formal analysis I.K., D.L.; writing-original draft preparation A.G., D.L., D.F.; writing-review and editing I.K. All authors have read and agreed to the published version of the manuscript.

Funding: The work was carried out with the support of the Program of Competitive Recovery of TSU, NU 8.2.10.2018 L.

Conflicts of Interest: The authors declare no conflict of interest. The founding sponsors had no role in the design of the study; in the collection, analyses, or interpretation of data; in the writing of the manuscript, and in the decision to publish the results.

\section{References}

1. Hench, L.L. Bioceramics. J. Am. Ceram. Soc. 1998, 81, 1705-1710.

2. Kokubo, T.; Kim, H.M.; Kawashita, M. Novel bioactive materials with different mechanical properties. Biomaterials 2003, 24, 2161-2175.

3. Catauro, M.; Bollino, F.; Papale, F. Investigation on bioactivity, biocompatibility, thermal behavior and antibacterial properties of calcium silicate glass coatings containing Ag. J. Non-Cryst. Solids 2015, 422, $16-$ 22.

4. Berezov, T.T. Biological Chemistry: Textbook; Berezov, T.T., Korovkin, B.F., 3rd ed.; Moscow: Meditsina, Russia; 1998; 704p.

5. Kulinets, I. Biomaterials and their applications in medicine. In Regulatory Affairs for Biomaterials and Medical Devices; 2015; pp. 1-10. Available online: http://www.sciencedirect.com/science/book/9780857095428 (accessed on 6 November 2020).

6. Doremus, R.H. Review: Bioceramics. J. Mater. Sci. 1992, 27, 285-297.

7. Lytkina, D.; Gutsalova, A.; Fedorishin, D.; Korotchenko, N.; Akhmedzhanov, R.; Kozik, V.; Kurzina, I. Synthesis and Properties of Zinc-Modified Hydroxyapatite. J. Funct. Biomater. 2020, 11, 10.

Publisher's Note: MDPI stays neutral with regard to jurisdictional claims in published maps and institutional affiliations.

(C) 2020 by the authors. Submitted for possible open access publication under the terms and conditions of the Creative Commons Attribution (CC BY) license (http://creativecommons.org/licenses/by/4.0/). 